\title{
Comparative Histomorphometric Analysis Between $\alpha$-Tcp Cement and $\beta$-Tcp/Ha Granules in the Bone Repair of Rat Calvaria
}

\author{
Gisela Grandi $^{\mathrm{a} *}$, Claiton Heitz ${ }^{\mathrm{b}}$, Luiz Alberto dos Santos ${ }^{\mathrm{c}}$, Miguel Luciano Silva ${ }^{\mathrm{d}}$, \\ Manoel Sant'Ana Filho ${ }^{\mathrm{b}}$, Rogerio Miranda Pagnocelli ${ }^{\mathrm{b}}$, Daniela Nascimento Silva ${ }^{\mathrm{b}}$ \\ ${ }^{a}$ School of Dentistry, Pontifícia Universidade Católica do Rio Grande do Sul - PUCRS, \\ Av. Ipiranga, 6681, CEP 90619-900, Porto Alegre, RS, Brazil \\ ${ }^{\mathrm{b}}$ Department of Surgery, Pontifícia Universidade Católica do Rio Grande do Sul - PUCRS, \\ Av. Ipiranga, 6681, CEP 90619-900, Porto Alegre, RS, Brazil \\ ${ }^{'}$ Department of Materials Engineering, Universidade Federal do Rio Grande do Sul-UFRGS, \\ Av. Osvaldo Aranha, 103, CEP 90035-190, Porto Alegre, RS, Brazil \\ ${ }^{\mathrm{d}}$ Department of Oral and Maxillofacial Surgery, Hospital Santa Casa de Porto Alegre, \\ Praça Dom Feliciano, 285, CEP 90020-160, Porto Alegre, RS, Brazil
}

Received: May 1, 2010; Revised: February 23, 2011

\begin{abstract}
This study compared the effect of two bioceramics on the process of bone repair: $\alpha$-tricalcium phosphate $(\alpha-\mathrm{TCP})$ cement and $\beta$-tricalcium phosphate hydroxyapatite particles $(\beta-\mathrm{TCP} / \mathrm{HA})$. Calvarial defects were created in 50 rats, divided into two groups ( $\alpha$ and $\beta / \mathrm{HA}$ ). Software was used at 7, 21, 60, 90 and 120 days to assess bone formation. Mean new bone formation rates were as follows: $\alpha$ group, $1.6 \%$ at 7 days, $5.24 \%$ at 21 days, $24 \%$ at 60 days, $30.21 \%$ at 90 days and $50.59 \%$ at 120 days; $\beta$ /HA group, $1.94 \%$ at 7 days, $2.53 \%$ at 21 days, $12.47 \%$ at 60 days, $26.84 \%$ at 90 days and $38.82 \%$ at 120 days; control group, $0.15 \%$ at 7 days, $10.12 \%$ at 21 days, $15.10 \%$ at 60 days, $18.94 \%$ at 90 days, $48.50 \%$ at 120 days. Both materials are osteoconductive and biocompatible. Perhaps the larger rate of new bone formation observed in the $\alpha$-TCP group, it also occurs in the $\beta$-TCP/HA group within a longer time period.
\end{abstract}

Keywords: bone defect, calcium phosphate

\section{Introduction}

Several studies have sought to develop or improve new and thriving biocompatible materials that favor the repair of bone defects in order to provide, restore and/or maintain bone volume and quality in regions with impaired anatomical structure. The advantages of alloplastic grafts include commercial availability, absence of donor-site morbidity, easy manipulation and conformation, in addition to the possibility of physical and/or chemical integration of the material into the grafted site ${ }^{1,2}$. Bone substitutes should have characteristics such as biocompatibility, nontoxicity and resistance to deformation. Resistance or not to resorption varies according to the desired application, and if biomaterials are resorbable, they should be metabolized by the body or eliminated by a normal physiological path $^{3-6}$.

Tricalcium phosphate (TCP) and hydroxyapatite (HA) are alloplastic bone substitutes that belong with the class of bioceramics. In recent years, they have been used in bone surgeries, and have shown numerous advantages in orthopedics and traumatology, such as biocompatibility and bioactivity, which allow for tissue osteoconduction and in situ hardening ${ }^{7,8}$. Alpha and beta-TCP have been used separately, in combination with each other or combined with $\mathrm{HA}^{9}$. HA, $\alpha$-TCP and $\beta$-TCP have similar chemical structures $\left(\alpha-\mathrm{Ca}_{3}\left(\mathrm{PO}_{4}\right)_{2}\right.$ and $\left.\beta-\mathrm{Ca}_{3}\left(\mathrm{PO}_{4}\right)_{2}\right)$, but they differ in their crystalline structure, which results in different absorption characteristics. The solubility of $\beta$-TCP is smaller than that of $\alpha$-TCP, which, in turn, is higher than that of HA. This implies longer permanence of $\beta$-TCP and of HA in the body ${ }^{9,10}$. TCPs are porous, resorbable, biocompatible materials, provoke little if any inflammatory response, permit the ingrowth of cells and vessels and have a direct connection with bony structure ${ }^{26,27}$.

According to Den Boer et al. ${ }^{11}$, several types of hydroxyapatite compounds have been tested for osteoconduction, and have yielded similar results to those obtained from autogenous grafts. Calcium phosphates, in general, are materials that can be easily manufactured into different compositions, sizes and shapes, depending on their specific application. They are characterized by relatively low tensile strength and low fatigue resistance ${ }^{9}$. The higher the number of small pores for a given total porosity, the more resistant the material will be ${ }^{12,26}$. Shima et al. ${ }^{13}$ reduced the size of cement granules in order to decrease pore size and thus increase mechanical strength of cement. Pores act as strength concentrators upon the mass, and the reduction in their size will also decrease the magnitude of the associated field of strength intensity ${ }^{14}$.

Calcium phosphate absorption rates are adjusted to various types of applications: filling, coating, bone cementing, and tissue regeneration. Solubility rates of calcium phosphate cannot be changed or modulated easily in a single phase, but if two phases of calcium phosphate are combined, these rates can be increased. Biphasic calcium phosphates, containing $\beta$-TCP and HA, have been intensively investigated due to their levels of bioactivity and osteoconductivity. The presence of calcium sulfate hemihydrate in the composition of $\alpha$-TCP cement allows reducing setting time, increasing $\mathrm{pH}$ values and forming pores in the cement to make osteoconduction 
easier ${ }^{1}$. According to Driessens et al. ${ }^{15}, \alpha$-TCP plus calcium sulfate hemihydrate provide a $\mathrm{pH}$ value between 6.5 and 8.0 , which allows for cellular activity. Among other properties, this cement does not swell or disintegrate when exposed to fluids, does not retract or expand, and does not release heat during the setting reaction ${ }^{6,27}$.

Generally, calcium phosphates are resorbed due to osteoclastic activity, forming new bone tissue at the bone-cement interface, thus characterizing the process of osteotransductivity. The speed at which this process occurs depends, among other factors, on the type of calcium phosphate tested, on the implantation site, and on the age of the recipient individual ${ }^{16}$.

The present study provided a histomorphometric analysis of the effect of $\alpha$-TCP cement and $\beta$-TCP/HA granules on the bone repair of critical calvarial defects in rats, with regard to osteoconductivity, quantifying and comparing the area of newly formed bone in both groups. The comparison between these materials is justified because they have the same indication as bone substitutes, but they have different physical structure, $\alpha$-TCP is cement developed in UFRGS Materials Engineering and $\beta$-TCP/HA are granules commercialized by Encobio SA. The presence of HA in $\beta$-TCP and its absence in $\alpha$-TCP is a factor to analysis in this article.

\section{Materials and Methods}

\subsection{Sample}

The sample consisted of 50 male adult rats (Ratthus norvegicus albinus, Wistar), weighing on average 300 to $400 \mathrm{~g}$, randomly distributed into two groups of 25 animals: Group- $\alpha$ and Group- $\beta$, according to the material inserted into the experimental cavity. The protocol was approved by the Animal Care and Use Committee of Pontifícia Universidade Católica do Rio Grande do Sul.

\subsection{Surgical procedure}

The animals were submitted to general anesthesia with ketamine chlorhydrate $50 \mathrm{mg} . \mathrm{kg}^{-1}(0.05 \mathrm{~mL} / 100 \mathrm{~g})$ and xylazine chlorhydrate $5 \mathrm{mg} . \mathrm{kg}^{-1}(0.025 \mathrm{~mL} / 100 \mathrm{~g})$, given intramuscularly. After hair removal from the upper region of the head, lidocaine chlorhydrate $2 \%$ with norepinephrine 1:50.000 was injected subcutaneously at the site in order to provide hemostasis and additional intraoperative analgesia, in addition to helping with pain management in the immediate postoperative period.

Surgical access was obtained by a linear coronal dermoperiosteal incision measuring $1.5 \mathrm{~cm}$ in length, between the outer auricles. The periosteum was divulsed and pulled apart along with the adjacent soft tissues, exposing the surface of parietal bones. Two cavities measuring $4 \mathrm{~mm}$ in diameter, one on each side of the sagittal suture, were made by using a cylindrical multiple blade bur, rupturing the outer and inner cortical, under profuse irrigation with physiological saline $0.9 \%$. Alpha-TCP cement and $\beta$-TCP/HA granules were inserted into the cavities on the left side, in their respective experimental group. Control cavities, bored into the right side of the calvarium, were not filled with material, but with blood from the surgical site (Figures 1 and 2). After repositioning of the soft tissues, including the repositioning of the periosteum over the cavities, the suture was made on a single plane using a 4.0 nylon thread (Mononylon ${ }^{\circledR}$, Ethicom).

Alpha-TCP cement (manufactured by Labiomat, Laboratory of Biomaterials of the School of Materials Engineering of Universidade Federal do Rio Grande do Sul, SANTOS, 2002) consists of a powder $(75 \%$ of $\alpha$-TCP and $15 \%$ of calcium sulfate hemihydrate, a composition with no similar description in the international literature), with addition of a solution containing accelerator $\left(2.5 \%\right.$ of $\left.\mathrm{Na}_{2} \mathrm{HPO}_{4}\right)$ until a cement consistency was obtained, being then inserted into

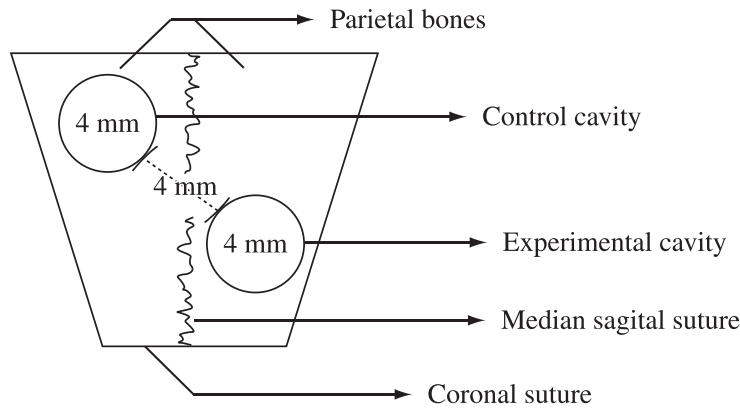

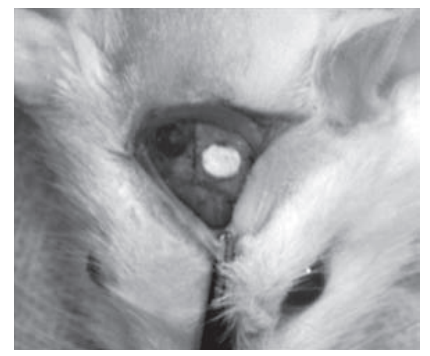

(a)

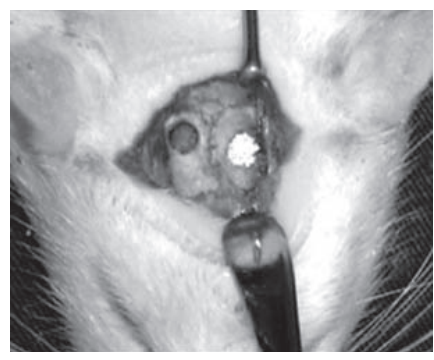

(b)
Figure. 1 Schematic representation of the rat calvarium. Bone cavities (experimental and control) bored into the parietal bones. Defects induced in the calvarium. Control cavity filled with blood clot in both groups. In a) experimental cavity $\alpha$, filled with $\alpha$-TCP cement. In b) experimental cavity $\beta$, filled with $\beta$-TCP/HA granules.

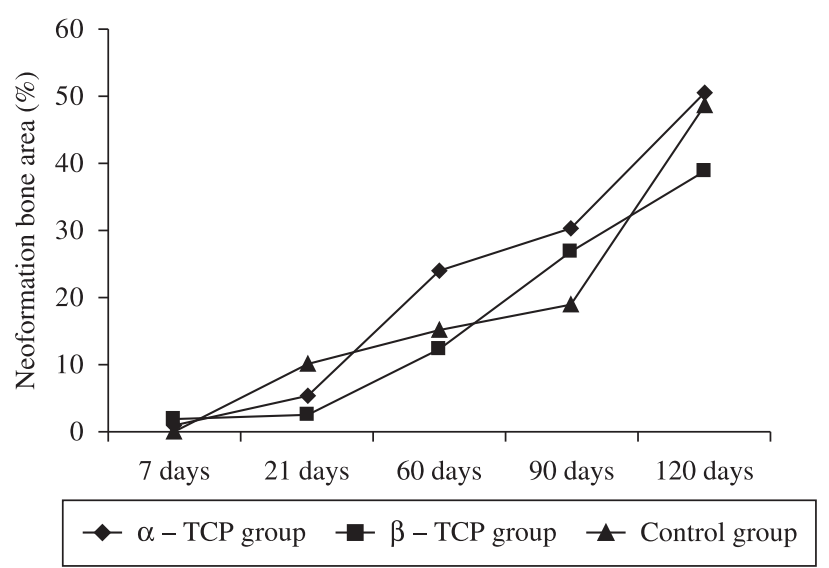

Figure 2. New bone formation in groups $\alpha, \beta$ and control in the observation periods.

experimental cavity $\alpha$. In group $\beta / \mathrm{HA}$, the cavity was filled with porous granules (mesh of $60-80$ ), containing $65 \%$ of HA and $35 \%$ of $\beta$-TCP (Osteosynt ${ }^{\circledR}$, EINCO Biomaterial Ltda.). The material was inserted into experimental cavity $\beta / \mathrm{HA}$, where it was mixed with blood from the surgical site.

The animals were killed postoperatively on days 7, 21, 60, 90 and 120 by isoflurane inhalation in a chamber and had their calvaria removed by osteotomy with a diamond blade under irrigation with physiological solution $0.9 \%$. After local macroscopic analysis, the surgical specimens were stored in neutral buffered formalin at $10 \%$ for over 24 hours and less than 72 hours.

\subsection{Slide preparation}

The surgical specimens were submitted to decalcification and routine histological processing for slide preparation, being then 
embedded in paraffin blocks. Thereafter, they were sectioned at a $6 \mu \mathrm{m}$ thickness in a microtome using the largest diameter of the defect, and stained with hematoxylin and eosin (HE) and analyzed under a light microscope.

\subsection{Slide analysis}

The histological images were captured from the microscope by the computer using $40 \times$ magnification. The slides were analyzed using Image Pro Plus, version $6.2^{\circledR}$, which allowed measuring the total area of each bone defect and the area of newly formed bone inside the defect. The measurement of the area (in micrometers) of newly formed bone was converted into a percentage value representing the total area of the defect. These percentage values were submitted to statistical analysis.

It was used completely randomized design, with two treatments applied in five periods, with three repetitions and one control group for each treatment and for each period. After to verify estimated to variance analysis (ANOVA) and being significant, the data had been compared by the Holm-Sidak test with $\mathrm{p}<0,05$. The results were evaluated for each treatment, compared with control, referring with application time and the treatments between itself had been compared. As the data had presented significance for ANOVA and to the test of comparison of averages, linear regression analysis in each type of treatment was applied in accordance with the application time.

\section{Results}

\subsection{Structure}

Alpha-TCP cement consists of a powder composed of $75 \%$ of $\alpha$-TCP $\left(\alpha-\mathrm{Ca}_{3}\left(\mathrm{PO}_{4}\right)_{2}\right)$ and $15 \%$ of calcium sulfate hemihydrates $\left(\mathrm{CaSO}_{4} \mathrm{H}_{2} \mathrm{O}\right)$, with addition of a solution containing accelerator ( $2.5 \%$ of $\mathrm{Na}_{2} \mathrm{HPO}_{4}$ ) until a cement consistency is obtained. Porous granules of $\beta / \mathrm{HA}$ contain $65 \%$ of $\mathrm{HA}\left(\mathrm{Ca}_{5}\left(\mathrm{PO}_{4}\right)_{3} \mathrm{OH}\right)$ and $35 \%$ of $\beta$-TCP $\left(\beta-\mathrm{Ca}_{3}\left(\mathrm{PO}_{4}\right)_{2}\right)$.

\subsection{Properties}

The percentage values of the mean new bone formation in the repair process in groups $\alpha$ and $\beta$ are shown in Table 1 . Note that there was a gradual increase in new bone formation in both groups throughout the five observation periods. New bone formation was higher in group $\alpha$ than in group $\beta$, at all observation times, with a statistically significant difference at 21 days and at 120 days. At the end of the experiment, the rate of new bone formation in group $\alpha$ amounted to $50.59 \%$, being higher than in the control group (48.50\%), which, in turn, had a larger area of new bone formation than group $\beta(38.8 \%)$.

The process of new bone formation is shown in Figure 3 in microscopic sections stained with HE, analyzed under a light microscope, at a $40 \times$ magnification, showing the comparison between groups $\alpha$ and $\beta$.

\subsection{Applications}

$\beta$-TCP/HA granules are resorbed more slowly than $\alpha$-TCP and seem to maintain the volume in the grafted region; therefore, their application can be indicated in cases of bone grafting to restore bone volume. Due to its high solubility rates, $\alpha$-TCP is indicated to replace grafts that precede titanium dental implants, in which the biomaterial needs to be quickly replaced with the newly formed bone.

\section{Discussion}

The characteristics observed in both phosphates corroborate the properties that are conceptually necessary, since they did not produce exacerbated inflammatory reaction, were not encapsulated or rejected by the body and allowed for osteoconduction ${ }^{1,18-20}$.

The comparison between $\alpha$-TCP cement and $\beta$-TCP/HA granules over time is important as it allows for predictability in the manipulation of the newly formed bone.

The results obtained in this study reveal a larger percentage of newly formed bone in cavities in which $\alpha$-TCP was used, with statistical significance. The $\alpha$-TCP block degraded significantly more than the $\beta$-TCP block $^{21}$. Hirakata ${ }^{22}$ and Li et al. ${ }^{10}$ asserted that the solubility and/or absorption rate of $\alpha$-TCP are higher than those of $\beta$-TCP. When the $\beta$-TCP crystal, in the cement phase, is mixed with water, it requires longer time to turn into calcium-deficient hydroxyapatite, therefore, remaining in the tissue and favoring osteoconduction. Perhaps this larger rate of new bone formation observed in the $\alpha$-TCP group also occurs in the $\beta$-TCP/HA group within a longer time period. According to Driessens et al. ${ }^{16}$, CFCs do not act as permanent bone substitutes, but they are slowly replaced.

By comparing the defects filled with $\alpha$-TCP cement with control defects, there was higher new bone formation in experimental cavities at 90 days, confirming the studies conducted by Jansen et al. ${ }^{23}$ and Kessler et al. ${ }^{24}$ In this same observation period, the mean rate of new bone formation of $26.84 \%$ in the $\beta$-TCP/HA group was higher than in the control group (18.94\%), and this difference was statistically significant; and smaller than in the $\alpha$-TCP group (30.32\%), without statistical significance. Alpha-tricalcium phosphate (alpha-TCP) ceramic is a bioresorbable material that degrades in bone tissue after implantation, since it exhibits higher solubility than beta-tricalcium phosphate (beta-TCP) ceramics. The high solubility of alpha-TCP in an aqueous solution causes its transformation into hydroxyapatite (HA) through hydrolysis ${ }^{28}$. To Nilen and Richter $^{29} \mathrm{HA} /$ beta-TCP ratio dominantly determines the rate and extent of $\mathrm{BCP}$ resorption in vivo, the possible thermal decomposition of HA during BCP synthesis must be considered, particularly if high temperature treatments are involved.

Table 1. Comparison of the area of new bone formation (mean and standard deviation, in \%) between groups $\alpha$ and $\beta$, according to observation periods.

\begin{tabular}{|c|c|c|c|c|c|c|c|}
\hline \multirow[t]{2}{*}{ Observation period } & \multicolumn{2}{|c|}{ Group $\alpha$} & \multicolumn{2}{|c|}{ Group $\beta$} & \multirow[t]{2}{*}{$\mathrm{p}$} & \multicolumn{2}{|c|}{ Control group } \\
\hline & Mean $(\%)$ & $\mathrm{SD}(\%)$ & Mean $(\%)$ & $\mathrm{SD}(\%)$ & & Mean $(\%)$ & $\mathrm{SD}(\%)$ \\
\hline 7 days & 1.06 & 2.37 & 1.94 & 3.10 & 0.629 & 0.15 & 0.33 \\
\hline 21 days & 5.24 & 5.58 & 2.53 & 1.19 & $0.004 *$ & 10.12 & 8.01 \\
\hline 60 days & 24 & 14.5 & 12.47 & 3.87 & 0.159 & 15.10 & 11.70 \\
\hline 90 days & 30.32 & 6.84 & 26.84 & 2.8 & 0.354 & 18.94 & 8.58 \\
\hline 120 days & 50.59 & 5.42 & 38.82 & 8.76 & $0.043 *$ & 48.50 & 14.40 \\
\hline
\end{tabular}

$\mathrm{SD}=$ Standard deviation. $*$ Statistically significant difference between groups $\alpha$ and $\beta(\mathrm{p}<0.05)$. 


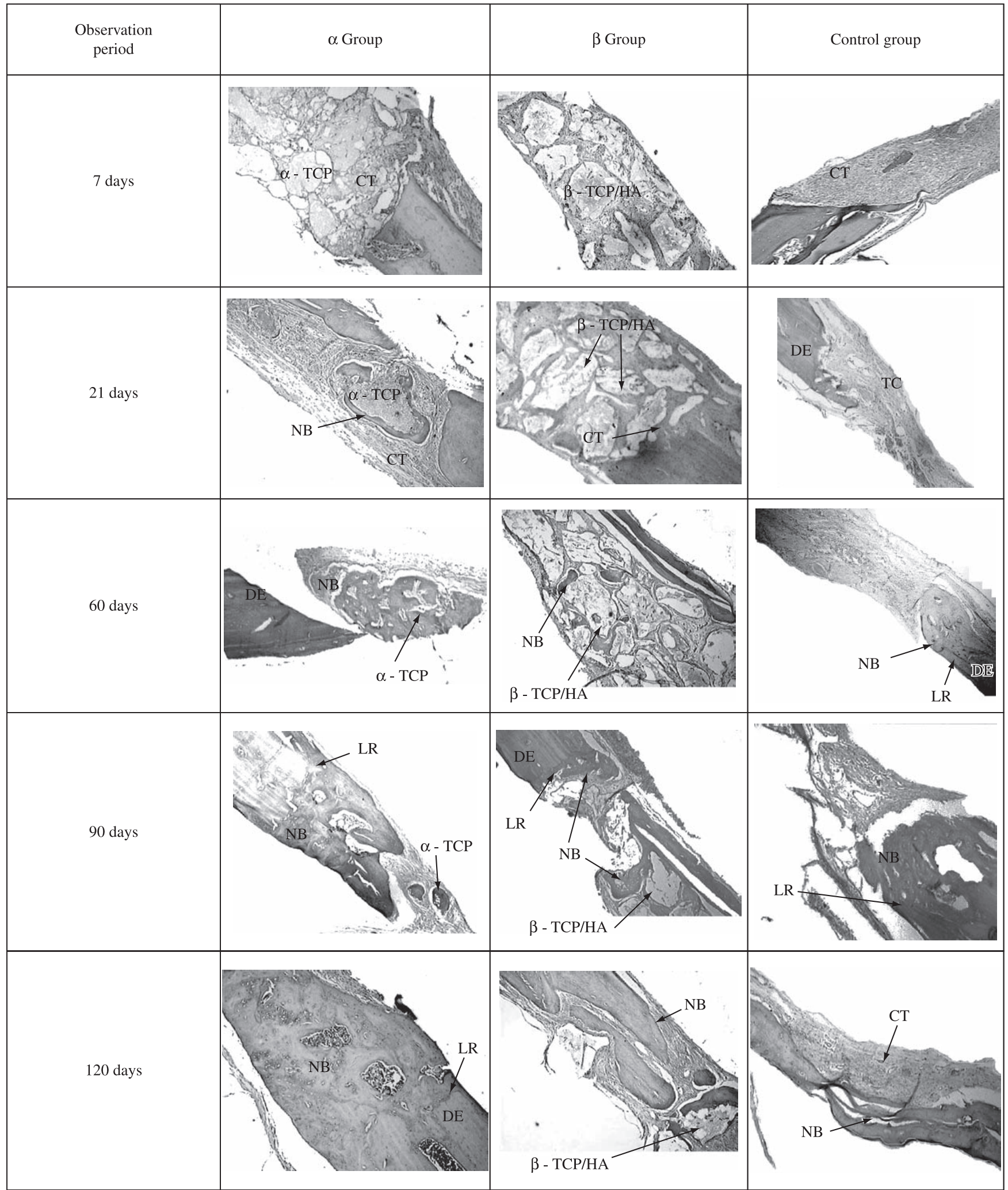

Figure 3. Comparison of the repair process between groups $\alpha, \beta$ and control: 7 days - In all groups: inflamatory infiltred cells. In test groups: there is material involved in conjunctive tissue (CT). 21 days - The standard of conjunctive tissue is more organized in all groups, showing new bone formation (NB) around materials granules in test groups. 60 days $-\alpha$ group: increase in neoformation bone area close to defect edges (DE) and around the material granules. $\beta$-TCP/HA group: more neoformation around the material granules. Control group: neoformation only in the defect edge. 90 days - Groups $\alpha$ and control: more neoformation in the edges, reversion line (RL) apparent. $\beta$-TCP/HA group: more neoformation around the granules. 120 days $-\alpha$ group: majority of defect is formed by new bone tissue, there is no granules of material. $\beta$-TCP/HA group: granules of material involved by new bone tissue and fibrous conjunctive tissue areas. Control group: band of new bone tissue filling part of the defect, but keeping fibrous conjunctive tissue in $2 / 3$ of the defect. 
In the present study, after 120 days, a larger amount of material was found in the defect in the $\beta$-TCP/HA group. Chow ${ }^{9}$ and $\mathrm{Li}$ et al. ${ }^{10}$ demonstrated that $\beta$-TCP has low solubility rates. According to information provided by the manufacturer of $\beta$-TCP/HA granules, hydroxyapatite was inserted in order to reduce the solubility of the bioceramics $^{25}$. The analysis of the defects induced in the present study reveals that the filling volume of granule-containing cavities was maintained, but that did not occur in the control cavities filled with blood clot.

This study showed higher mean rates of new bone formation in the $\alpha$-TCP group. These results are due to the cement structure, since its crystals have an open structure, with pore formation caused by calcium sulfate hemihydrate ${ }^{1}$, which allows for the formation of the osteoid matrix amidst the crystals. On the other hand, $\beta$-TCP/HA granules, as they have a structure in which the crystals are larger and less soluble ${ }^{22}$, were kept for a longer time inside the defect. This promoted new bone formation, although in a smaller amount than in the former group, and maintained tissue volume inside the defect. Observations in periods longer than 120 days would be necessary for elucidating the effect of the materials analyzed here on bone repair.

Based on the results obtained and on literature reports, both materials are believed to have the necessary properties for clinical use. In cases in which a higher bone volume is required, such as in the correction of defects with esthetic involvement, $\beta$-TCP/HA may be indicated. However, in cases in which earlier formation of bone tissue is necessary, for instance in grafts that precede dental implants, $\alpha$-TCP cement provides quicker new bone formation. These materials have specific indications depending on their solubility into the tissue and on the speed at which they promote osteoconduction.

Alpha-TCP cement and $\beta$-TCP/HA granules used promote osteoconduction and are biocompatible. Alpha-TCP cement is more soluble and allows for a larger new bone formation area, compared to $\beta$-TCP/HA granules and to the blood clot (control). Beta-TCP/HA granules are resorbed more slowly and seem to maintain the volume in the grafted region.

\section{Acknowledgements}

This study received financial support from Coordenação de Aperfeiçoamento de Pessoal de Nível Superior (CAPES), Laboratory of Biomaterials of the School of Materials Engineering of Universidade Federal do Rio Grande do Sul, and Osteosynt ${ }^{\circledR}$ - EINCO Biomaterial Ltda.

\section{References}

1. Santos LA. Desenvolvimento de cimento de fosfato de cálcio reforçado por fibras para uso na área médico-odontológica. [Dissertation]. Campinas, Brazil: Universidade Estadual de Campinas; 2002.

2. Martinelli F, Lima L and Tirre-Araujo M. Guideline for planning the multidisciplinary rehabilitation of dental mutilated patients. Revista Odonto Ciência [series on the internet]. 2006; 21:92-96. Available from: <http://revistaseletronicas.pucrs.br/fo/ojs/index.php/fo/article/ view/1088/864>. Access in: Nov. 2008.

3. Ousterhout DK and Stelnicki EJ. Plastic surgery's plastics. Clinics in Plastic Surgery. 1996; 23:183-90.

4. Valerio P, Pereira MM, Goes AM and Leite MF. The effect of ionic products from bioactive glass dissolution on osteoblast proliferation and collagen production. Biomaterials. 2004; 25:2941-8.

5. Knabe C, Stiller M, Berger G, Reif D, Gildenhaar R, Howlett CR et al. The effect of bioactive glass ceramics on the expression of bone-related genes and proteins in vitro. Clinical Oral Implants Research. 2005; 16:119-27.

6. Shayegan A, Petein M and Abbeele AV. Beta-tricalcium phosphate, white mineral trioxide aggregate, white Portland cement, ferric sulfate, and formocresol used as pulpotomy agents in primary pig teeth. Oral Surgery,
Oral Medicine, Oral Pathology, Oral Radiology \& Endodontics. 2008; 105:536-42.

7. Nilen RWN and Richter PW. The thermal stability of hydroxyapatite in biphasic calcium phosphate ceramics. Journal of Materials Science: Materials in Medicine. 2008; 19:1693-702.

8. Jafarian M, Eslaminejad MB, Khojasteh A, Mashhadi Abbas F, Dehghan MM, Hassanizadeh R et al. Marrow-derived mesenchymal stem cellsdirected bone regeneration in the dog mandible: a comparison between biphasic calcium phosphate and natural bone mineral. Surgery, Oral Medicine, Oral Pathology, Oral Radiology \& Endodontics. 2008; 105:e14-e24.

9. Chow LC. Calcium phosphate materials: reactor response. Advances in Dental Research. 1988; 2:181-4.

10. Li Y, Weng W and Tam KC. Novel highly biodegradable biphasic tricalcium phosphates composed of $\beta$ - tricalcium phosphate and $\beta$ tricalcium phosphate. Acta Biomaterialia. 2007; 3:251-4.

11. den Boer FC, Wippermann BW, Blokhuis TJ, Patka P, Bakker FC and Haarman HJ. Healing of segmental bone defects with granular porous hydroxyapatite augmented with recombinant human osteogenic protein-1 or autologous bone marrow. Journal of Orthopaedic Research. 2003; 21:521-8.

12. Mindess S. Relationships between strength and microstructure for cement-based materials: an overview. In: Very high strength concretebased-materials. Materials Research Society. 1985;42:53-68.

13. Shima T, Keller JT, Alvira MM, Mayfield FH and Dunsker SB. Anterior cervical discectomy and interbody fusion. An experimental study using syntetic tricalcium phosphate. Journal of Neurosurgery. 1979; 51:533-8.

14. Alford NM. A theoretical argument for the existence of high strength cement pastes. Cement and Concrete Research. 1981; 11:605-10.

15. Driessens FC, Fernández E, Ginebra MP, Boltong MG and Planell JA. Calcium phosphates and ceramic bone cements vs. acrylic cements. Anales de Quimica International Edition. 1997; 93:S38-S43.

16. Driessens FC, Planell JA, Boltong MG, Khairoun I and Ginebra MP. Osteotransductive bone cements. Proceedings of the Institution of Mechanical Engineers. Part H. 1998; 212:427-35.

17. Moon HJ, Kim KN, Kim KM, Choi SH, Kim CK, Kim KD et al. Effect of calcium phosphate glass on bone formation in calvarial defects of Sprague-Dawley rats. Journal of Materials Science: Materials in Medicine. 2006; 17:807-13.

18. Kurashina K, Kurita H, Kotani A, Takeuchi $\mathrm{H}$ and Hirano M. In vivo studies of a calcium phosphate cement consisting of alpha-tricalcium phosphate/dicalcium phosphate dibasic/tetracalcium phosphate monoxide. Biomaterials. 1997; 18:147-51.

19. Ohura K, Bohner M, Hardouin P, Lemaître J, Pasquier G and Flautre B. Resorption of, and bone formation from, new $\alpha$ - tricalcium phosphate monocalcium phosphate cements: an in vivo study. Journal of Biomedical Materials Research. 1996; 30:193-200.

20. Shayesteh YS, Khojasteh A, Soleimani M, Alikhasi M, Khoshzaban A and Ahmadbeigi N. Sinus augmentation using human mesenchymal stem cells loaded into a $\beta$-tricalcium phosphate/hydroxyapatite scaffold. Surgery, Oral Medicine, Oral Pathology, Oral Radiology \& Endodontics. 2008; 106:203-9.

21. Yamada M, Shiota M, Yamashita Y and Kasugai SJ. Histological and histomorphometrical comparative study of the degradation and osteoconductive characteristics of $\alpha$ - and $\beta$ - tricalcium phosphate in block grafts. Journal of Biomedical Materials Research. Part B, Applied biomaterials. 2007; 82:139-48.

22. Hirakata LM. Development and evaluation of apatite with modification by a - tricalcium phosphate. [Dissertation]. Kuramoto, Japan: The University of Tokushima, 2001.

23. Jansen JA, de Ruijter JE, Schaeken HG, Van Der Waerden JP, Planell JÁ and Driessens FC. Evaluation of tricalcium phosphate/ hidroxiapatite cement for tooth replacement: an experimental animal study. Journal of Materials Science: Materials in Medicine. 1995; 6:653-7. 
24. Kessler S, Mayr-Wohlfart U, Ignatius A, Puhl W, Claes L and Günther KP. Histomorphological, histomorphometrical and biomechanical analysis of ceramic bone substitutes in a weight-bearing animal model. Journal of Materials Science: Materials in Medicine. 2002; 13:191-5.

25. Einco Biomaterial. Descrição da biocerâmica fosfocálcica bifásica micromacroporosa de TCP/HA. (Osteosynt $\left.{ }^{\circledR}, 2007\right)$. Available from: <http:// www.eincobio.com.br.>. Access in: 27 oct. 2007.

26. Nakagawa A, Matsuya S, Takeuchi A and Ishikawa K. Comparison of the effects of Added $\alpha$ and $\beta$ tricalcium phosphate on the basic properties of apatite cement. Dental Materials Journal. 2007; 26(3):342-347.
27. Seebach C, Schultheiss J, Wilhem K, Frank J and Henrich D. Comparison of six bone-graft substitutes regarding to cell seeding efficiency, metabolism and growth behavior of human mesenchymal stem cells (MSC) in vitro. International Journal of the Care of the Injured. 2010; 41:731-8.

28. Uchino T, Yamaguchi K, Suzuki I, Kamitakahara M, Otsuka M and Ohtsuki C. Hydroxyapatite formation on porous ceramics of alphatricalcium phosphate in a simulated body fluid. Journal of Materials Science: Materials in Medicine. 2010; 21(6):1921-6.

29. Nilen RW and Richter PW. The thermal stability of hydroxyapatite in biphasic calcium phosphate ceramics. Journal of Materials Science: Materials in Medicine. 2008; 19(4):1693-702. 